\title{
Healthcare Service Standardization in U.S. and European Countries Fei HOU ${ }^{1, a}$, Li-Li CAO ${ }^{1, b, *}$, Yi ZENG ${ }^{1, c, *}$, Yong-Hong CHENG ${ }^{1, d, *}$ \\ ${ }^{1}$ China National Institute of Standardization, Beijing, China \\ ahoufei@cnis.gov.cn, ${ }^{b}$ caoll@cnis.gov.cn, czengyi@cnis.gov.cn, ${ }^{d}$ chengyh@cnis.gov.cn
}

${ }^{*}$ Corresponding author

\begin{abstract}
Key Words: Healthcare Service Standardization, U.S. and European Countries.
\end{abstract}
\begin{abstract}
Along with the rapid development of the healthcare service industry all over the world in recent years, various developed countries have begun to pay greater attention to and attach greater significance to related standardization activities; a series of effective measures have been taken and desirable results have been achieved. This paper explores and analyzes the status of standardization in the healthcare service industry conducted in U.S. and European Countries as U.S., U.K., Germany, France, selects typical cases, and sums up good practices. Against the background of China's booming healthcare service industry, the paper aims to provide successful experience and good reference for carrying out related work.
\end{abstract}

\section{Introduction}

At present, with the improvement of living standards and rapid development of medical and healthcare technology, the public's demand on life expectancy and life quality is increasingly high. Against this background, healthcare service industry across the world has received extensive attention and gained greater significance; various countries share a common vision of helping people live a healthier, happier and more comfortable life.

In recent years, standardization, as an important technological means of improving the development and management of service industry, is very popular. Many developed countries, such as U.S., U.K., Germany, and France, have made a series of exploration of and attempts at standardization of healthcare service industry, and have made remarkable achievements.

\section{U.S.}

As the most developed country in the world, U.S. has already established a mature system for healthcare service. Relevant laws and regulations, rules of the industry, personnel training and qualification, and government and social supporting mechanism are complete and systematic; the division of healthcare fields and categories and the rights and responsibilities of relevant parties are clear and explicit.

As the most typical follower of the economic theory of laissez-faire among developed countries, U.S. government has limited capacity to intervene in the details of specific operations of the service industry. At the federal level, U.S. government mainly identifies minimum "threshold" requirements and targets for the service industry in the form of laws and regulations; technological standards are usually promulgated and implemented by industry association and enterprises. Healthcare service industry is no exception, and in terms of laws and regulations and rules of the industry, US has promulgated dozens of federal regulations, such as 42 CFR Part 51b - "Project grants for preventive health services" and 2 CFR 136.24 - "Authorization for contract health services", specifying basic and critical elements of healthcare service industry.

At the level of standards and standardization, U.S. government began to establish and implement an access control and standardization reporting system for all healthcare service institutions as early as 1997. U.S. National Association of Social Workers also successively issued such associational standards as NASW Standards For Social Work Practice In Health Care Settings, NASW Standards For Social Work Practice In Palliative And End Of Life Care and NASW Standards For Social 
Work Services In Long-Term Care Facilities, providing technical basis and guidance for social workers' participation in various kinds of healthcare work; American National Standards Institute has also issued the national standard, ANSI/NFPA99-2005 "Health Care Facilities", putting forward the requirements for nationwide healthcare facilities; what's more, after long-term practice, many U.S. healthcare service institutions have released service standards or administrative rules of their own, laying a solid foundation for the improvement of overall quality of U.S. healthcare service industry.

\section{U.K.}

As a capitalist and typical welfare country, UK is famous for the comprehensiveness, universality and applicability of its social welfare system, and is notable for many practices in terms of healthcare service. Created in 1948, the National Health Service (hereinafter referred to as "NHS") was one of the core elements of the welfare system of UK. It is widely acclaimed by the UK public and universally admired by international community for its features of government operation, funding from taxes, broad coverage, comprehensive service, and regional balance. UK Department of Health is in charge of the standardization of NHS, issuing plenty of guidance and standards for NHS in the forms of many policy documents, health announcement and executive notice, to guarantee the quality of healthcare service.

In recently years, impacted by the overall economic situation, UK social welfare system has experienced twists and turns from rapid development to predicament, to transformations. UK government cannot cope with the public's increasing demands and expectations for healthcare service. In order to relieve the pressure, while optimizing and reforming the NHS, UK government has begun to encourage the development of private healthcare service system. However, compared with NHS, private healthcare service system is still in a subordinate and supplementary position in terms of both overall scale and funding.

To regulate market oriented healthcare service, UK established Health Service Audit and Supervision Committee in 2003, responsible for the regulation of the provision and implementation of all health service, the collection of performance evaluation data, and rating for health service providers. Moreover, such organizations and institutions as General Medical Council, Royal College of Physicians and King's Fund have released relevant standards and requirements for healthcare service.

\section{Germany}

As one of the forerunners in service standardization, Germany attaches great importance to service standardization, takes the leading position in the field of international service standardization, and serves as the Secretariat of various ISO Technical Committees related to service standardization. Statistics show that DIN has issued and implemented more than four thousand international standards in the field of medical and health service, including healthcare service, taking the first place in major developed countries.

Germany attaches great importance to healthcare service industry. According to statistics of the German Federal Statistics Office, Germany healthcare service industry has been rapidly developing in recent years. Against the background of continued growth of global service trade, healthcare service with the brand of "Made in Germany" has become a new star in Germany service trade. The elaborate products and standardized service of Germany are very popular in many countries. Therefore, Germany launched the Healthcare Industry Export Initiative, vigorously promoting the export of Germany healthcare service and the collective brand of Germany healthcare service.

To support the rapid development and expansion of its healthcare service both at home and abroad, Germany has undertaken various activities of healthcare service industry standardization, successively issuing such national standards as DIN 5035-3-2006 Artificial Lighting, Part III: Healthcare Room Lighting, DIN 1946-4-2008 Ventilation and Air Conditioning, Part IV: Healthcare Service Facilities Ventilation, DIN EN 15224-2012 Healthcare Service Quality 
Management System, DIN EN 16224-2012 Spine Medical and Healthcare Specification and DIN EN 12381-2006 Health Informatics, Time Specification for Special Case Healthcare, and adopting such series of ISO standards as Sterilization of health-care products, Sterilization of health care products - Radiation, and Health informatics, so as to standardize healthcare service industry in terms of internal management, technical support and external service.

\section{France}

With a long tradition of rule by law, France passed "Declaration of the Rights of Man and of the Citizen" as early as 1789 after the French Revolution, which together with French Civil Code laid the foundation for the "hierarchical" social management of France; at the same time, as a typical welfare state, France also has a healthcare service system of long history, and above all, 30 years of rapid development after World War II laid solid the economic foundation for France to establish "the best healthcare service system in the world".

So far, France has promulgated and implemented such national standards for the healthcare service industry as NF C71-025-1995 Light Source, Part II: Special Requirements, Section 25: Light Source Used by the Hospital and Healthcare Building Clinic, NF S91-301-2009 Dentistry, Information System of Dental Equipment Location in Dental Healthcare Provider Working Area and NF S99-139-2013 Healthcare Service, Quality Management System, and NF S99-137-2004 Physical Therapy and Recovery, Consolidated Primary Method, Service Commitment. At the same time, France, similar to Germany, learns from other countries and organizations in the field of healthcare service industry standardization, and adopt ISO standards, including dozens of standards in the Healthcare Informatics series.

In terms of service accreditation, all the accreditation of French healthcare service organizations, as well as medical organizations, are carried out by French National Health Administration. What's more, French National Health Administration also created a special website for quality comparison of medical and healthcare organizations in 2013, which centralized massive information about the service quality of medical and healthcare organizations scattered on the network, so as to help the public know and compare nationwide medical and healthcare organizations and choose service suitable for themselves.

\section{Acknowledgement}

This research was financially supported by China National Institute of Standardization.

\section{References}

[1] Fei HOU. Social Management and Public Service Standardization, Situation and Trend Abroad [J]. China Standardization, 2012(11).60-63+68

[2] Liang YING. Learning from Japan's Experience in Preventive Healthcare in China's Establishment of Family - based Healthcare System. [J]. Chinese Journal of Family Planning 2013 (3). $155-160$ 